\title{
Real-World Outcomes of Intravitreal Aflibercept for Neovascular Age-Related Macular Degeneration: A Large-Scale Postmarketing Surveillance in Korea
}

\author{
Gahyung Ryu (1D) ${ }^{1,2}$ \\ Donghyoun Noh ${ }^{1,2}$ \\ Guihyun Moon ${ }^{3}$ \\ Min Sagong $\mathbb{D}^{1,2}$
}

'Department of Ophthalmology, Yeungnam University College of Medicine, Daegu, Republic of Korea;

${ }^{2}$ Yeungnam Eye Center, Yeungnam University Hospital, Daegu, Republic of Korea; ${ }^{3}$ Bayer Korea Ltd, Seoul, Republic of Korea
Correspondence: Min Sagong

Department of Ophthalmology, Yeungnam University College of Medicine,

170 Hyunchungro, Nam-gu, Daegu,

424I5, Republic of Korea

Tel +82-53-620-3443

Fax +82-53-626-5936

Email msagong@yu.ac.kr
Purpose: To investigate the efficacy and safety of intravitreal aflibercept (IVT-AFL) in Asian patients with neovascular age-related macular degeneration (nAMD) in a real-world clinical setting.

Patients and Methods: In this analysis of a prospective, regulatory, postmarketing surveillance study for IVT-AFL, 3115 patients with nAMD were included and followed for 8 months. The mean changes in best-corrected visual acuity (BCVA) and central retinal thickness (CRT) were analyzed using last observation carried forward method. A post hoc subgroup analysis and a multivariate logistic regression analysis were also performed to assess factors related to treatment outcomes.

Results: Mean BCVA improved from 0.62 to 0.51 logarithm of minimum angle resolution and mean CRT decreased from 383.3 to $289.7 \mu \mathrm{m}$, with a mean of 3.4 injections during the 8-month follow-up. In the subgroup analysis, patients who had received 3 initial monthly doses had significantly better anatomical improvements than those treated as needed. Patients with confirmed polypoidal choroidal vasculopathy (PCV) had significantly better anatomical improvements and better visual recovery than those with other types of nAMD. The multivariate regression analysis demonstrated that age, injection number, PCV, and baseline BCVA were significantly associated with higher odds of gaining 3 lines at 8 months, and sex, injection number, PCV, and baseline CRT were associated with CRT $\leq 250 \mu \mathrm{m}$ at 8 months. No new safety findings were identified.

Conclusion: IVT-AFL was effective and well tolerated in a real-world setting with a large number of Asian patients with nAMD. Number of injections and PCV were important determinants for improved treatment outcomes.

Keywords: aflibercept, Asian, neovascular age-related macular degeneration, polypoidal choroidal vasculopathy, postmarketing surveillance, real-world

\section{Introduction}

Age-related macular degeneration (AMD) is one of the leading causes of blindness in adults older than 65 years. ${ }^{1}$ As the aging population grows, the number of patients with AMD is expected to continue to increase. ${ }^{2-5}$ Currently, the established standard of care for neovascular AMD (nAMD) is anti-vascular endothelial growth factor (VEGF) agents. ${ }^{6}$

Although many landmark clinical trials have shown that anti-VEGF treatment may optimise functional outcomes, generalisability and replication of findings in the real world can be limited by protocol-required inclusion/exclusion criteria and 
treatment patterns during clinical trials that result in a high degree of motivation for treatment, and regular followup. $^{7-10}$

Real-world evidence suggests that anti-VEGF treatment is not always dosed according to recommendations and patients generally receive fewer doses than label recommendations, sometimes resulting in substantial differences in treatment outcomes compared with clinical trials. ${ }^{11-13}$ Additionally, most international clinical trials predominantly include white patients, whereas the characteristics of nAMD in East Asian populations differ in many respects. For example, in East Asian populations, it is more common to observe male preponderance, a higher rate of polypoidal choroidal vasculopathy (PCV), a lower rate of retinal angiomatous proliferation, and genetic variants associated with AMD. ${ }^{14-22}$

Intravitreal aflibercept (EYLEA ${ }^{\circledR}$, Regeneron, Tarrytown, NY, and Bayer HealthCare, Berlin, Germany), a fusion protein with binding domains from VEGF receptors, has been reported to have a substantially higher binding affinity for VEGF and potentially longer duration of action in the eye than ranibizumab (Lucentis ${ }^{\circledR}$, Genentech, Inc., San Francisco, CA, USA) or bevacizumab (Avastin ${ }^{\circledR}$; Genentech, Inc., San Francisco, CA, USA). ${ }^{23,24}$ Although several studies have investigated the efficacy and safety of intravitreal aflibercept (IVT-AFL) in Asian patients with nAMD, most of the studies have taken place retrospectively or in a randomised controlled trial setting in small samples of Asian patients with nAMD. ${ }^{25-29}$ The current study investigates the effectiveness and safety of IVT-AFL in a realworld clinical setting in Korean patients with nAMD, using large-scale postmarketing surveillance (PMS) study data.

\section{Materials and Methods}

\section{Korean PMS Study: An Observational Study}

This study was a prospective, multicenter, observational study. After approving IVT-AFL for nAMD in March 2013 by the Korean Ministry of Food and Drug Safety, the regulatory PMS study was conducted from May 2014 to March 2019 to evaluate the clinical safety and effectiveness of IVT-AFL in routine clinical practice. According to the Ministry of Food and Drug Safety guidelines, the minimum regulatory requirement for recruitment was 3000 patients; but assuming a $20 \%$ drop-out rate, 3750 patients were sought. Patients who were diagnosed with nAMD and for whom IVT-AFL was planned to be given for the first time were enrolled. Patients who received any other anti-VEGF agent within 90 days prior to enrollment were excluded from the PMS study.

\section{Study Population}

As of March 2019, 3189 patients were enrolled in the PMS study. Of these, 3169 patients who had at least 1 injection were included in the safety analysis set excluding 1 duplicate patient, 9 patients who had consented prior to the contract date of the study sites, 8 patients who had did not receive IVT-AFL, and 2 patients in whom inclusion/ exclusion criteria were not met. Among those 3169 patients who were included in the safety analysis set for the PMS study, 3115 patients with nAMD were included in the safety analysis set for this post hoc analysis of PMS study. Patients in the safety analysis set who had both baseline data and at least 1 effectiveness data measurement after injection comprised the effectiveness set. Further, 2864 patients who had at least one best-corrected visual acuity (BCVA) measurement after injection were included in the BCVA effectiveness analysis set, and 2932 patients who had at least one central retinal thickness (CRT) measurement after injection were included in the CRT effectiveness analysis set. The disposition of patients in this study is described in Figure 1

\section{Study Outcomes and Measurements}

The primary efficacy outcome measure was the mean change in BCVA over 8 months. The secondary outcome measures were mean change in CRT over 8 months, mean number of injections during follow-up, number of cases with systemic and ocular adverse events (AEs) and adverse drug reactions (ADRs, where the causal relationship was assessed by the clinician and the AE considered an ADR unless the causal relationship was "unlikely").

Demographics and baseline characteristics including medical history and previous ocular treatment were collected at the first visit. Data on subtype of nAMD were determined based on investigators' clinical judgment. Fluorescein angiography and indocyanine green angiography were not mandatory. Thus, the cases with diagnostic ambiguity were classified as unknown. Effectiveness data, assessed using BCVA and CRT, were collected at every visit. BCVA was evaluated using Snellen charts and converted to logarithm of minimum angle resolution ( $\log$ MAR) for statistical analysis. The number of IVTAFL injections administered overall and visit frequency were also collected. The incidence of AEs and ADRs that 


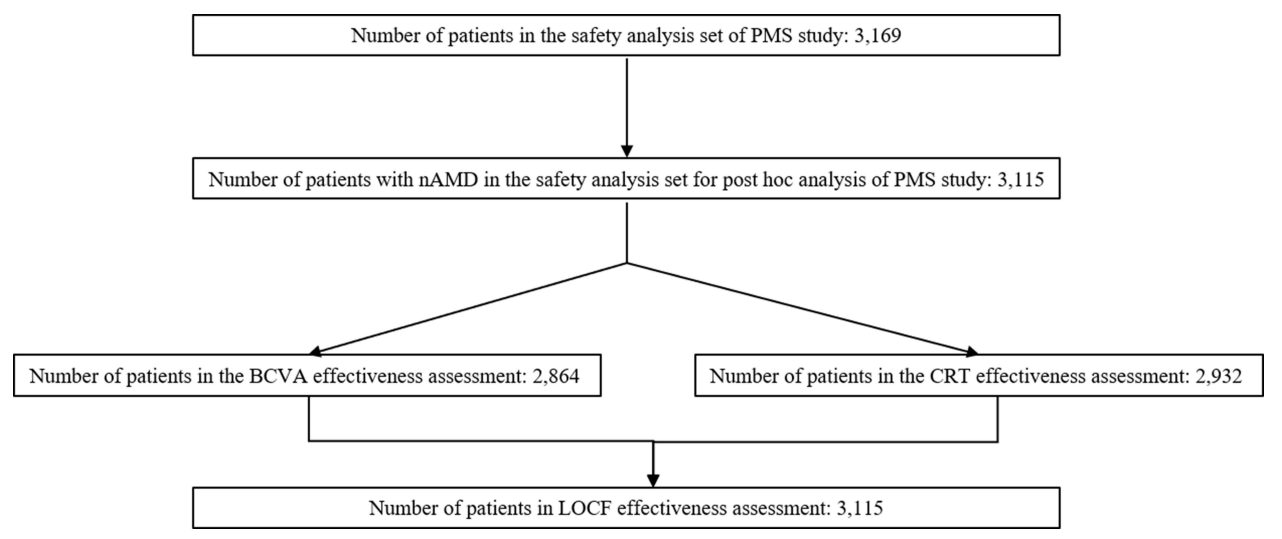

Figure I Distribution of patients included in the study.

Abbreviations: BCVA, best-corrected visual acuity; CRF, case report form; CRT, central retinal thickness; LOCF, last observation carried forward; nAMD, neovascular agerelated macular degeneration.

could not be excluded from a causal relationship with IVTAFL injection during follow-up were also evaluated as a safety analysis. AEs were classified as system organ class and preferred term using MedDRA version 21.1. The case number of reported AEs, ADRs, serious AEs, and serious ADRs were summarised by dividing into systemic and ocular AEs.

\section{Statistical Analysis}

Changes in BCVA and CRT after IVT-AFL treatment were assessed using the paired $t$ test. The missing data for BCVA and CRT during the study were analyzed using last observation carried forward (LOCF). Eyes were classified into three groups by BCVA changes as improved (BCVA improvement $\geq 0.3 \log \mathrm{MAR}$ ), maintained (BCVA change $<0.3 \log \mathrm{MAR}$ ), and deteriorated (BCVA worsening $\geq 0.3 \log$ MAR). Subgroup analysis was performed according to administration of three initial monthly doses defined as at least three injections at intervals of 1 month \pm 14 days (complete initial doses vs incomplete initial doses) or nAMD subtype (PCV vs non-PCV). Chi-square test or Fisher's exact test for categorical data and $t$ test for continuous variables were performed to compare baseline characteristics and effectiveness between subgroups. To investigate factors associated with any visual acuity (VA) improvement of more than 3 lines ( $0.3 \log$ MAR) and CRT under $250 \mu \mathrm{m}$ at 8 months, a multivariate logistic regression analysis was then performed including factors that were significant in the univariate analysis. The analyses were performed using SAS, version 9.4 (SAS Institute Inc., Cary, NC, USA), and the test statistics were the results of two-sided tests with a statistically significant level of 0.05 .

\section{Results}

\section{Baseline Characteristics}

At baseline, mean age was $70.0 \pm 8.9$ years and $61.8 \%$ of the patients were male. Mean BCVA was $0.62 \pm 0.40$ $\log$ MAR, and mean CRT was $383.3 \pm 138.2 \mu \mathrm{m}$. Mean duration of nAMD was $16.3 \pm 119.9$ days (median, 1 day; Q1-Q3, 1 day-6 days), and $96.3 \%$ of patients had nAMD diagnosis for less than 1 month. Of all patients, 99.3\% were treatment naïve, and of the $0.7 \%$ of pretreated patients, injections of other anti-VEGF agents $(61.9 \%)$ were the most common pretreatment, followed by photocoagulation (19.1\%), photodynamic therapy (9.5\%), and surgery (9.5\%). PCV (26.5\%) was the most common subtype of nAMD, although the type of nAMD was unknown in $24.4 \%$ (Table 1 ).

As a result of IVT-AFL treatment over 8 months, patients were administered an average of $3.4 \pm 1.0$ injections and visited the hospital for a total of $4.5 \pm 1.5$ visits (Table 2). Among the 3115 patients, 1150 (36.9\%) were followed-up for more than 8 months. These patients were administered an average of $3.6 \pm 1.0$ injections and had an average of $5.7 \pm 0.6$ visits in 8 months.

\section{Visual and Anatomical Outcomes}

Mean BCVA improved from $0.62 \pm 0.40 \log$ MAR at baseline to $0.57 \pm 0.40$ at 1 month, $0.54 \pm 0.41$ at 2 months, 0.54 \pm 0.41 at 3 months, $0.52 \pm 0.41$ at 4 months, $0.52 \pm 0.41$ at 5 months, $0.51 \pm 0.41$ at 6 months, $0.51 \pm 0.41$ at 7 months, and $0.51 \pm 0.42$ at 8 months $(P<0.001$ for all time points $)$ 
Table I Baseline Patient Demographics and Disease Characteristics

\begin{tabular}{|c|c|}
\hline Variable & Total $(n=3 \mid 15)$ \\
\hline Age (years) & $70.0 \pm 8.9$ \\
\hline \multicolumn{2}{|l|}{ Age Group, n (\%) } \\
\hline$<50$ years & $21(0.7)$ \\
\hline $50-59$ years & $398(12.8)$ \\
\hline $60-69$ years & $1052(33.8)$ \\
\hline $70-79$ years & $1182(38.0)$ \\
\hline$\geq 80$ years & $462(14.8)$ \\
\hline \multicolumn{2}{|l|}{ Sex, n (\%) } \\
\hline Male & $1925(61.8)$ \\
\hline Female & $1190(38.2)$ \\
\hline Baseline BCVA, logMAR & $0.62 \pm 0.40$ \\
\hline Duration of nAMD, days (median; QI, Q3) & $16.3 \pm 119.9(1.0 ; 1.0,6.0)$ \\
\hline \multicolumn{2}{|l|}{ Duration Category ${ }^{\mathrm{a}}, \mathrm{n}(\%)$} \\
\hline$<1$ month & $2266(96.3)$ \\
\hline $1-<3$ months & $4 \mid(1.7)$ \\
\hline$\geq 3$ months & $46(2.0)$ \\
\hline Pretreatment of nAMD, $n(\%)$ & $21(0.7)$ \\
\hline PDT & $2(9.5)$ \\
\hline Photocoagulation & $4(19.1)$ \\
\hline Surgery & $2(9.5)$ \\
\hline Other anti-VEGF agents & $13(61.9)$ \\
\hline \multicolumn{2}{|l|}{ Subtype of nAMD, n (\%) } \\
\hline PCV & $825(26.5)$ \\
\hline Non-PCV & I529 (49.1) \\
\hline Occult CNV & $622(40.7)$ \\
\hline Predominantly classic CNV & $604(39.5)$ \\
\hline Minimally classic CNV & $189(12.4)$ \\
\hline RAP & $100(6.5)$ \\
\hline Other & $14(0.9)$ \\
\hline Unknown & $76 \mid(24.4)$ \\
\hline
\end{tabular}

Notes: Values are mean \pm standard deviation unless otherwise noted. ${ }^{\mathrm{a}} \mathrm{A}$ total of 762 patients were excluded for analysis of duration.

Abbreviations: BCVA, best-corrected visual acuity; CNV, choroidal neovascularization; logMAR, logarithm of the minimum angle of resolution; $\mathrm{nAMD}$, neovascular age-related macular degeneration; PCV, polypoidal choroidal vasculopathy; PDT, photodynamic therapy; RAP, retinal angiomatous proliferation; VEGF, vascular endothelial growth factor.

(Figure 2A). The proportion of patients whose BCVA improved by more than $0.3 \log$ MAR gradually increased from $12.46 \%$ at 1 month to $24.6 \%$ at 8 months. Furthermore, during the observation period, less than $8 \%$ of patients had a deterioration in vision of $\geq 0.3 \log$ MAR (Figure 3).

The mean CRT declined from $383.3 \pm 138.2 \mu \mathrm{m}$ at baseline to $317.0 \pm 124.4 \mu \mathrm{m}$ at 1 month, $299.3 \pm 120.7 \mu \mathrm{m}$ at 2 months, $295.4 \pm 119.1 \mu \mathrm{m}$ at 3 months, $289.2 \pm 115.2 \mu \mathrm{m}$ at 4 months, $289.0 \pm 113.9 \mu \mathrm{m}$ at 5 months, $289.5 \pm 113.4 \mu \mathrm{m}$
Table 2 Treatment Exposure Over 8 Months

\begin{tabular}{|c|c|}
\hline Variables & Total $(n=3|| 5)$ \\
\hline Mean number of injections & $3.4 \pm 1.0$ \\
\hline \multicolumn{2}{|l|}{ Patients with I to 5 Injections, n (\%) } \\
\hline I injection & $215(6.9)$ \\
\hline 2 injections & $518(16.6)$ \\
\hline 3 injections & 1376 (44.2) \\
\hline 4 injections & $596(19.1)$ \\
\hline 5 injections & $410(13.2)$ \\
\hline Mean number of visits & $4.5 \pm 1.5$ \\
\hline \multicolumn{2}{|l|}{ Patients with I to 6 Visits, n (\%) } \\
\hline I visit & $66(2.1)$ \\
\hline 2 visits & $277(8.9)$ \\
\hline 3 visits & $586(18.8)$ \\
\hline 4 visits & $540(17.3)$ \\
\hline 5 visits & 491 (15.8) \\
\hline 6 visits & II55 (37.I) \\
\hline
\end{tabular}

Note: Values are mean \pm standard deviation unless otherwise noted.

at 6 months, $291.0 \pm 114.8 \mu \mathrm{m}$ at 7 months, and 289.7 $\pm 112.9 \mu \mathrm{m}$ at 8 months $(P<0.001$ for all $)$ (Figure $2 \mathrm{~B})$.

\section{Subgroup Analysis of Outcomes Depending on Initial Dosing Regimen}

Of the 3115 patients whose data were analyzed, 733 patients who received less than 3 injections during the study period were excluded. Of the remaining 2382 patients, 1759 patients (73.8\%) received three initial monthly doses. Comparing those who completed three initial monthly doses to patients that did not, the group that completed initial dosing had fewer males (60.3\% vs $65.8 \%, P=0.014$ ), a shorter mean nAMD duration ( $8.5 \pm 59.0$ days vs $28.2 \pm 168.5$ days, $P=0.009$ ), and received more injections ( $3.6 \pm 0.8$ injections vs $3.5 \pm 0.7$ injections, $P<$ 0.001 ), although there was no significant difference in age or the presence of pretreatment between groups (Supplementary Table S1).

The BCVA at every month was found to be generally improved in those who received three initial monthly doses compared with those that did not, but a significant difference was observed only at 7 months (Figure 4A). CRT reduction was also greater in those with three initial monthly injections, and significant differences were observed at every month except for the first month and third month (Figure 4B).

\section{Subgroup Analysis of Outcomes Depending on Subtype of nAMD}

Comparing the 825 patients with confirmed PCV (26.5\%) and 1529 patients with non-PCV (49.1\%) (Table 1), the 

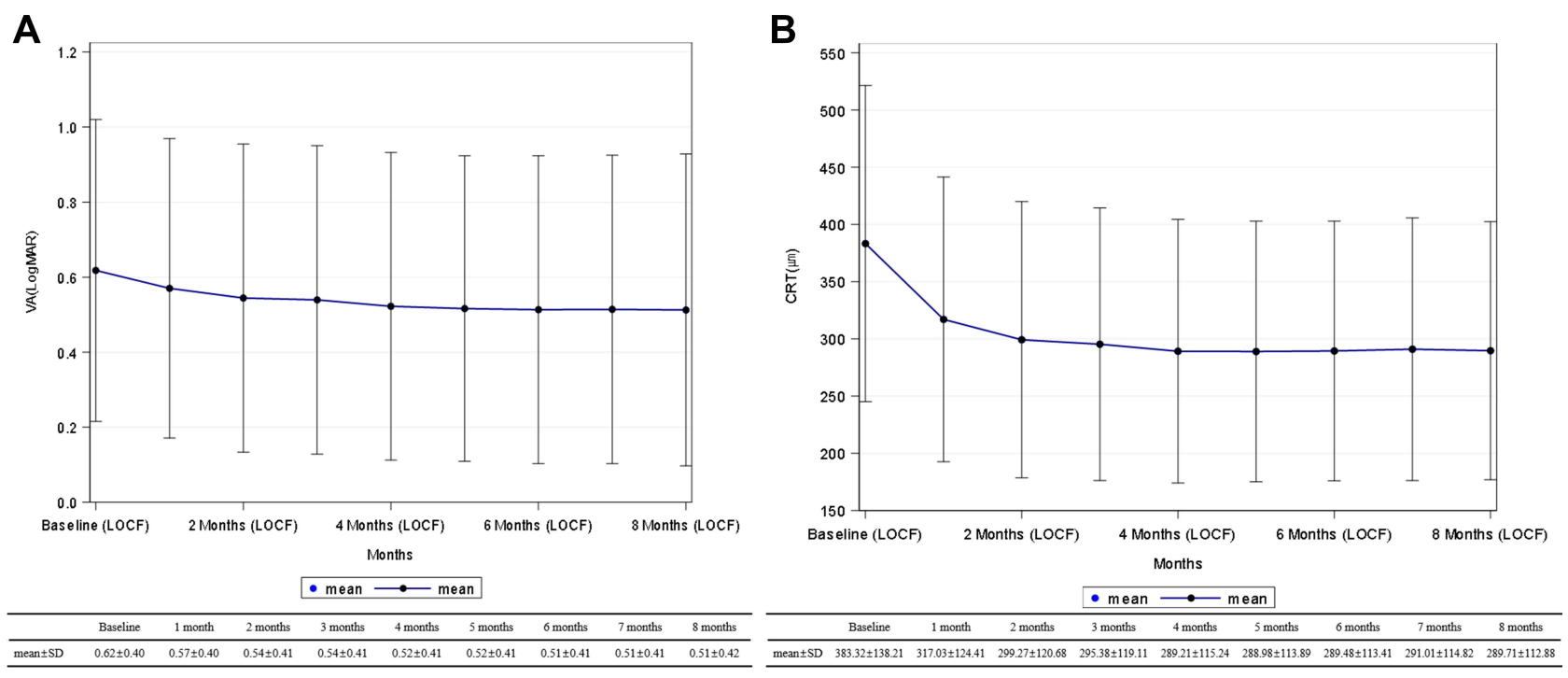

Figure 2 BCVA and CRT over 8 months. (A) BCVA (logMAR), (B) CRT $(\mu \mathrm{m})$.

Abbreviations: BCVA, best-corrected visual acuity; CRT, central retinal thickness; LOCF, last observation carried forward; logMAR, logarithm of minimum angle resolution.

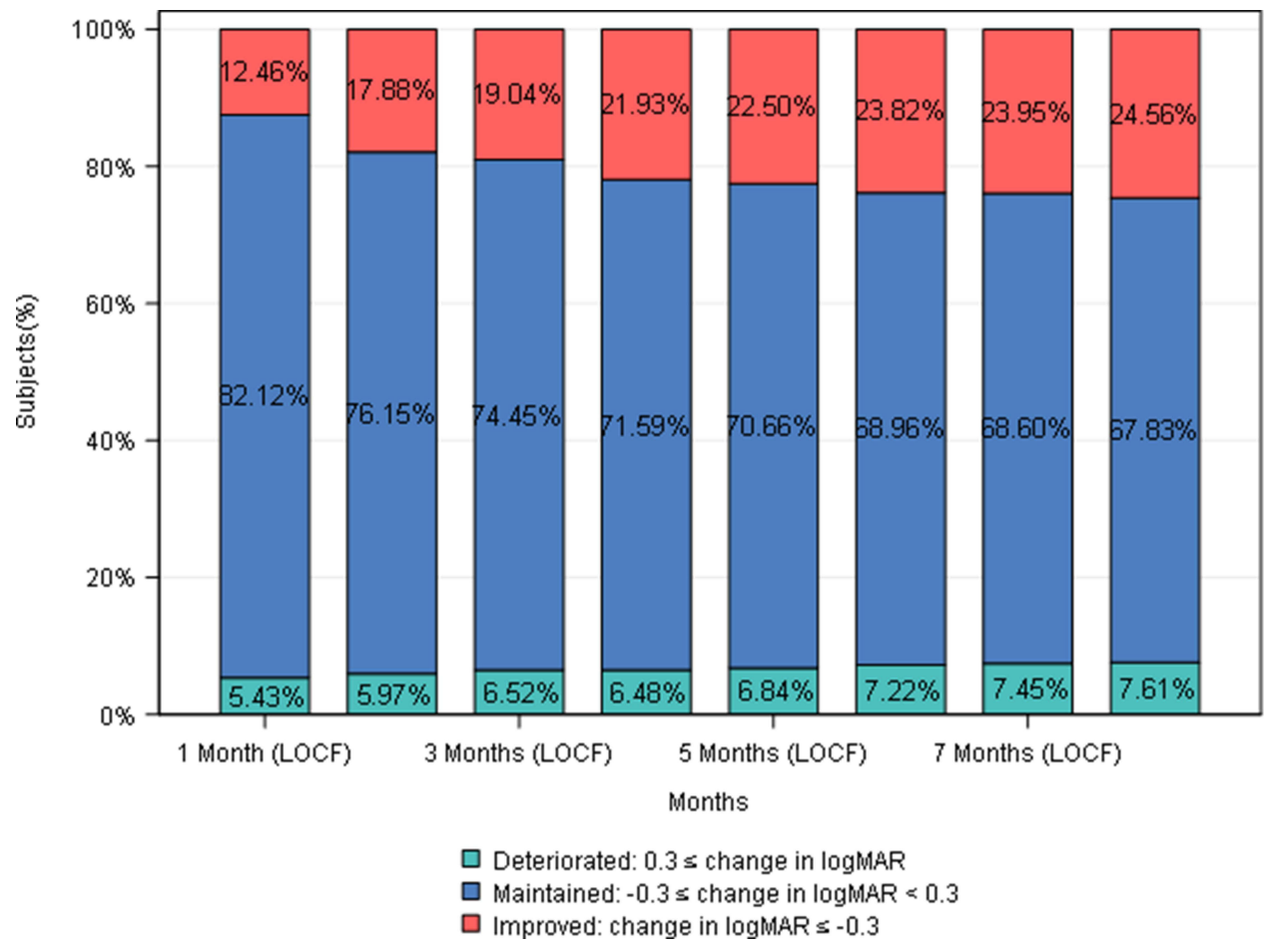

Figure 3 Proportion of patients with vision outcome (3 categories) compared to baseline.

Abbreviations: LOCF, last observation carried forward; logMAR, logarithm of minimum angle resolution.

PCV patient group was younger $(68.9 \pm 8.9$ years vs 71.6 \pm 9.0 years, $P<0.001$ ), included more males (male $69.0 \%$ vs $60.2 \%, P<0.001)$, and had more injections $(3.4 \pm 1.0$ injections vs $3.2 \pm 1.1$ injections, $P<0.001$ ), although there was no significant difference of disease duration and the presence of pretreatment between groups (Supplementary Table S2).
The BCVA was generally improved in the PCV group compared with non-PCV group at every month, but significant differences were observed only after 3 months (Figure 5A). CRT reduction was also greater in the PCV group compared patients without $\mathrm{PCV}$, and significant differences were observed at every month except for the first, 4th, and 5th month (Figure 5B). 
A

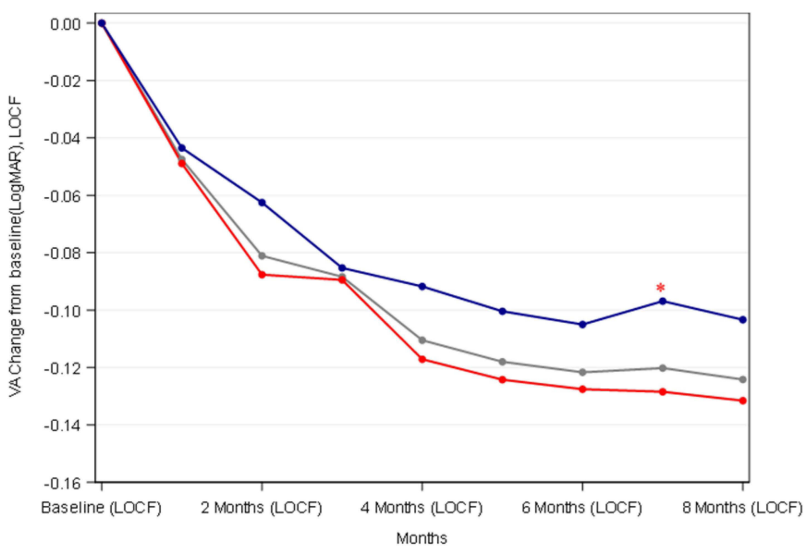

B

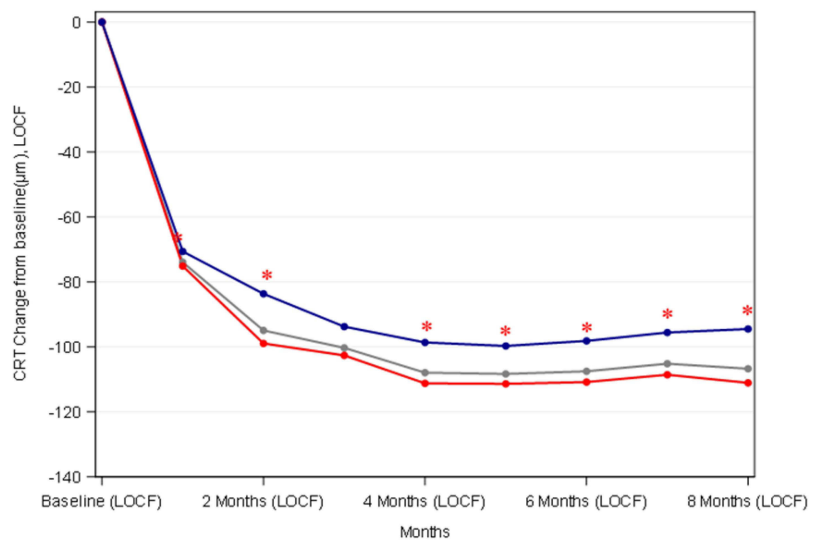

$\longrightarrow$ Total $\longrightarrow$ Loading dose complete $\longrightarrow$ Loading dose incomplete

$\longrightarrow$ Total $\longrightarrow$ Loading dose complete $\longrightarrow$ Loading dose incom plete

\begin{tabular}{|c|c|c|c|c|c|c|c|c|c|c|c|c|c|c|c|c|c|c|c|}
\hline LOCF & Baseline & 1 month & 2 months & 3 months & 4 months & 5 months & 6 months & 7 months & 8 months & LOCF & Baseline & 1 month & 2 months & 3 months & 4 months & 5 months & 6 months & 7 months & 8 months \\
\hline Total & 0 & $-0.05 \pm 0.24$ & $-0.07 \pm 0.28$ & $-0.08 \pm 0.29$ & $-0.10 \pm 0.30$ & $-0.10 \pm 0.31$ & $-0.10 \pm 0.32$ & $-0.10 \pm 0.33$ & $-0.11 \pm 0.34$ & Total & 0 & $-663 \pm 97.9$ & $-84.1 \pm 110.0$ & $-88.0 \pm 113.8$ & $-94.1 \pm 117.3$ & $-94.4 \pm 120.3$ & $-93.8 \pm 122.4$ & $-92.3 \pm 121.9$ & $-93.6 \pm 122.1$ \\
\hline $\begin{array}{l}\text { Loading dose } \\
\text { complete }\end{array}$ & 0 & $-0.05 \pm 0.25$ & $-0.09 \pm 0.30$ & $-0.09 \pm 0.31$ & $-0.12 \pm 0.32$ & $-0.12 \pm 0.33$ & $-0.13 \pm 0.34$ & $-0.13 \pm 0.35$ & $-0.13 \pm 0.36$ & \begin{tabular}{|l|} 
Loading dose \\
complete
\end{tabular} & 0 & $-75.1 \pm 100.8$ & $-98.9 \pm 114.4$ & $-102.6 \pm 116.9$ & $-111.2 \pm 121.0$ & $-111.3 \pm 125.5$ & - $-110.8 \pm 127.4$ & $4-108.6 \pm 127.1$ & $-111.0 \pm 126.4$ \\
\hline $\begin{array}{l}\text { Loading dose } \\
\text { incomplete }\end{array}$ & 0 & $-0.04 \pm 0.26$ & $-0.06 \pm 0.27$ & $-0.09 \pm 0.30$ & $-0.09 \pm 0.30$ & $-0.10 \pm 0.33$ & $-0.11 \pm 0.32$ & $-0.10 \pm 0.33$ & $-0.10 \pm 0.33$ & $\begin{array}{l}\text { Loading dose } \\
\text { incomplete }\end{array}$ & 0 & $-70.6 \pm 105.6$ & $-83.6 \pm 111.0$ & $-93.7 \pm 122.6$ & $-98.6 \pm 122.5$ & $-99.7 \pm 1239$ & $-98.1 \pm 1289$ & $-95.6 \pm 127.0$ & $-94.5 \pm 128.6$ \\
\hline $\begin{array}{l}\text { P-value } \\
\text { (t-test) }\end{array}$ & & 0.649 & 0.056 & 0.770 & 0.076 & 0.116 & 0.154 & 0.043 & 0.073 & $\begin{array}{l}\begin{array}{l}\text { P-value } \\
\text { (t-test) }\end{array} \\
\end{array}$ & & 0.344 & 0.004 & 0.109 & 0.026 & 0.046 & 0.034 & 0.028 & 0.005 \\
\hline
\end{tabular}

Figure 4 Mean change of BCVA and CRT depending on initial monthly dosing status (whether patients received three initial injections given at intervals of $I$ month \pm 14 days). (A) Mean change of BCVA depending on initial monthly dosing status. (B) The mean change of CRT depending on the initial monthly dosing status. $* P<0.05$.

Abbreviations: BCVA, best-corrected visual acuity; CRT, central retinal thickness; LOCF, last observation carried forward; logMAR, logarithm of minimum angle resolution.

A

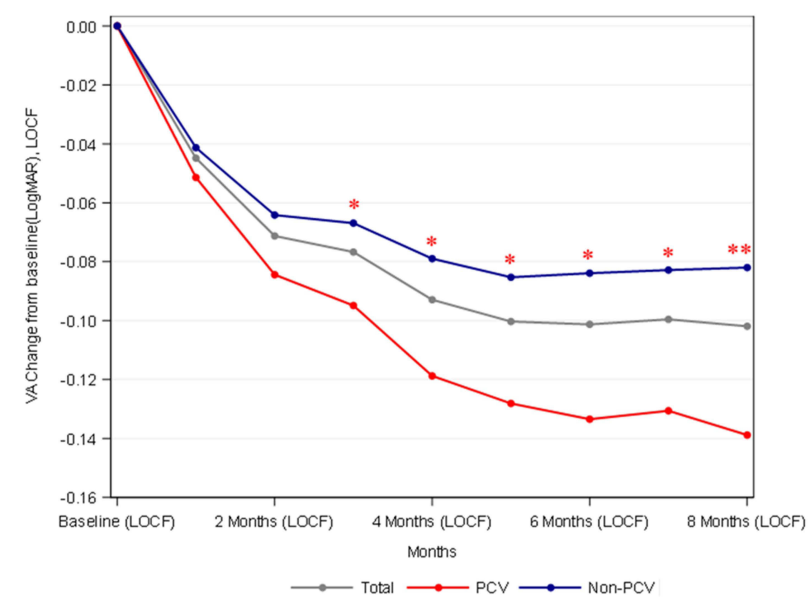



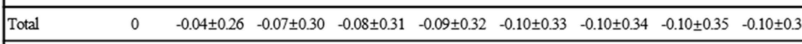
\begin{tabular}{lllllllllll}
\hline PCV & 0 & $-0.05 \pm 0.26$ & $-0.08 \pm 0.32$ & $-0.09 \pm 0.32$ & $-0.12 \pm 0.33$ & $-0.13 \pm 0.33$ & $-0.13 \pm 0.34$ & $-0.13 \pm 0.35$ & $-0.14 \pm 0.35$
\end{tabular}

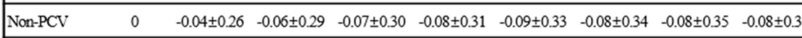
\begin{tabular}{|lllllllll|}
\hline $\begin{array}{l}\text { P-value } \\
\text { (t-t-est) }\end{array}$ & 0.369 & 0.128 & 0.042 & 0.004 & 0.003 & 0.001 & 0.002 & $<0.001$ \\
\hline
\end{tabular}
B



$\longrightarrow$ Total $\longrightarrow$ PCV $\longrightarrow$ Non-PCV

\begin{tabular}{|c|c|c|c|c|c|c|c|c|c|}
\hline LOCF & Baseline & 1 month & 2 months & 3 months & 4 months & 5 months & 6 months & 7 months & 8 months \\
\hline Total & 0 & $-74.5 \pm 106.5$ & $-92.1 \pm 118.1$ & $-96.9 \pm 122.2$ & $-102.3 \pm 125.8$ & $-102.5 \pm 129.5$ & $5-101.2 \pm 131.9$ & $-99.0 \pm 131.7$ & $-99.9 \pm 131.6$ \\
\hline PCV & 0 & $-79.0 \pm 108.3$ & $-100.3 \pm 122.0-$ & $-1062 \pm 124.9$ & $-109.2 \pm 126.9$ & $-108.5 \pm 126.9$ & $-109.8 \pm 128.3$ & $-108.2 \pm 129.0$ & $-108.0 \pm 126$. \\
\hline Non-PCV & 0 & $-72.2 \pm 105.4$ & $-87.6 \pm 115.7$ & $-91.9 \pm 120.4$ & $-98.6 \pm 125.1$ & $-99.3 \pm 130.8$ & $-96.6 \pm 133.6$ & $-94.0 \pm 132.9$ & $-95.5 \pm 134.1$ \\
\hline $\begin{array}{l}\text { P-value } \\
\text { (t-test) }\end{array}$ & & 0.138 & 0.013 & 0.007 & 0.052 & 0.099 & 0.021 & 0.013 & 0.028 \\
\hline
\end{tabular}

Figure 5 Mean change of BCVA and CRT depending on subtypes of nAMD. (A) The mean change of BCVA depending on subtypes of nAMD (PCV vs non-PCV). (B) the mean change of CRT depending on subtypes of nAMD (PCV vs non-PCV). $* P<0.001, * * P<0.05$.

Abbreviations: BCVA, best-corrected visual acuity; CRT, central retinal thickness; LOCF, last observation carried forward; logMAR, logarithm of minimum angle resolution. 
Table 3 Multivariate Regression Analysis Associated with BCVA and CRT Outcome at 8 Months

\begin{tabular}{|c|c|c|c|c|}
\hline \multirow[t]{2}{*}{ Variables } & \multicolumn{2}{|c|}{ 3-Line Gainers } & \multicolumn{2}{|c|}{ CRT $\leq 250 \mu \mathrm{m}$} \\
\hline & P-value & OR $(95 \% \mathrm{Cl})$ & P-value & OR $(95 \% \mathrm{Cl})$ \\
\hline Age, years & $<0.001$ & $0.97(0.96,0.98)$ & 0.057 & $1.01(1.00,1.02)$ \\
\hline Sex, male vs female & 0.647 & $1.05(0.86,1.27)$ & 0.027 & $0.83(0.71,0.98)$ \\
\hline Number of injections & $<0.001$ & $1.56(1.45,1.68)$ & $<0.001$ & $\mathrm{I} .43(1.35, \mathrm{I} .5 \mathrm{I})$ \\
\hline Subtype of nAMD (patients with vs without confirmed PCV) & 0.001 & $1.44(1.16,1.78)$ & 0.007 & $1.28(1.07,1.53)$ \\
\hline Baseline CRT, $\mu \mathrm{m}$ & 0.385 & $1.00(1.00,1.00)$ & $<0.001$ & $0.99(0.99,0.99)$ \\
\hline \multicolumn{5}{|l|}{ Baseline BCVA, logMAR ${ }^{a}$} \\
\hline \multicolumn{5}{|l|}{ First Quartile } \\
\hline Second quartile & $<0.001$ & $15.58(8.68,27.96)$ & 0.100 & $0.84(0.68,1.04)$ \\
\hline Third quartile & $<0.001$ & $4 I .44(23.27,73.8 I)$ & 0.717 & $\mathrm{I} .04(0.84,1.29)$ \\
\hline Fourth quartile & $<0.001$ & $98.00(54.56,176.03)$ & 0.236 & $1.16(0.91,1.47)$ \\
\hline
\end{tabular}

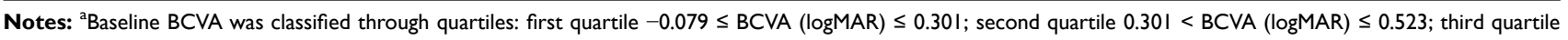
$0.523<$ BCVA $(\log M A R) \leq 0.824$; fourth quartile $0.824<B C V A(\log M A R) \leq 2.000$.

Abbreviations: BCVA, best-corrected visual acuity; Cl, confidence interval; CRT, central retinal thickness; nAMD, neovascular age-related macular degeneration; OR, odds ratio; PCV, polypoidal choroidal vasculopathy.

\section{Multivariate Analysis of Factors Associated with Treatment Outcomes at 8 Months}

A multivariate regression analysis indicated that younger age $(P<0.001)$, frequent injections $(P<0.001)$, PCV $(P=$ $0.001)$, and having a worse baseline BCVA $(P<0.001)$ were significantly associated with higher odds of gaining 3 lines at 8 months. Additionally, females $(P=0.027)$, having frequent injections $(P<0.001)$, PCV $(P=0.007)$, and a lower baseline CRT $(P<0.001)$ were significantly associated with higher odds of a CRT less than $250 \mu \mathrm{m}$ at 8 months (Table 3).

\section{Safety Outcomes}

Eight months after initiation of IVT-AFL, a total of 46 systemic $(1.22 \%)$ and 67 ocular AEs (1.83\%) and 21 systemic $(0.61 \%)$ and 41 ocular $(1.22 \%)$ ADRs were reported. Among the reported AEs, a total 10 systemic serious AEs and 1 serious ADR were reported. Details of safety outcomes are presented in Supplementary Table S3-S6.

The occurrence and incidence of AEs were consistent with those observed in other studies and no new safety signals were observed during the 8 months after initiation of IVT-AFL treatment. ${ }^{10}$

\section{Discussion}

This study reports a visual gain of $0.11 \log$ MAR (equivalent to 5 letters) at 8 months. This improvement is approximately 3-4 letters better than that reported in the 1-year results of the pivotal VIEW 1 and 2 trials (7.9 letters in VIEW 1 and 8.9 letters in VIEW 2). ${ }^{10}$ Although the 8-month results were not specifically reported in those trials, the results from 1 year were used for comparison as BCVA improvement plateaued after 3 initial monthly doses and was maintained for up to 1 year. $^{10}$ Differences in BCVA outcomes between realworld evidence studies and clinical trials are not unexpected since real-world evidence studies should allow for the inclusion of eyes with a wider range of baseline BCVA and choroidal neovascularization lesions, as well as those with structural damage at the fovea, and may include confounders such as cataracts, which would be excluded from clinical trials. Further, BCVAs recorded here are not equivalent to refracted protocol-standardised VA measurements seen in clinical trials, and as such, may show less VA gained compared with a clinical trial-recorded VA measurement. Fewer injections may also have influenced the results. The injection number of the patients in VIEW 1 and VIEW 2 trials during 1-year was 7.5 injections and that of this observational study during 8 months was 3.4 injections. ${ }^{10}$ The results from previous studies revealed that although anti-VEGF treatment resulted in an initial improvement in BCVA, this was not maintained over time in real clinical practice due to treatment discontinuation. ${ }^{30-}$ 32 In this study, only $36.9 \%$ of patients completed the 8 -month study period, but even these patients received an 
average of 3.6 injections, which was not significantly different from the overall average, suggesting that flexible dosing in a real-world setting may result in fewer injections.

Despite the above observations, approximately 92.4$94.6 \%$ of patients improved or maintained vision for the 8-month observation period, and CRT reduction at month 8 was $-93.61 \mu \mathrm{m}$. Considering that 1 -year result seen in clinical trials $(-128.5 \mu \mathrm{m}$ in VIEW 1 and $-149.2 \mu \mathrm{m}$ in VIEW 2), the difference of CRT was approximately 34.89 $\mu \mathrm{m}$ and $55.59 \mu \mathrm{m}$, respectively. ${ }^{10}$ In clinical trials, CRT was reduced rapidly by week 4 and maintained at week 52. ${ }^{10}$ Similarly, initial improvements in BCVA and CRT were maintained up to 8 months in this observational study. The results are comparable with previous clinical trials, precluding the possibility of significant undertreatment in real-world settings, despite fewer injections.

Although there are fewer studies evaluating real-world efficacy of IVT-AFL for nAMD because of its more recent approval, the results of our study of an approximately 5-letter BCVA gain over 8 months are also favourable compared with the previous IVT-AFL observational studies. In the 12-month outcome of the RAINBOW study, conducted on 586 French patients with nAMD, the mean change in BCVA at 8 months was demonstrated to be between 5.0 letters at 6 months and 5.5 letters (4.5 letters using LOCF approach) at 12 months. ${ }^{33}$ Similarly, an observational study including 197 eyes from the Fight Retinal Blindness database reported BCVA improvement of 4.3 letters at 12 months, and 109 eyes from retrospective analysis of electronic medical record in United Kingdom reported BCVA improvement of 5.4 letters at 12 months. $^{34,35}$ However, observational studies including larger datasets reported reduced visual improvements; 2.9 \pm 16.8 letters at 12 months in a study including 848 German patients with nAMD, $2.74 \pm 7.06$ letters at 12 months in a study including 31 Portugal patients with nAMD, and -0.39 letters at 12 months in a study including 4300 American patients with nAMD ${ }^{36-38}$ Although direct comparison is not possible due to the different study periods and demographics, our study reported relatively superior results with more than 3000 patients, most likely because most patients were treatment naïve and had a shorter disease duration. Korean patients can easily visit retinal clinics without referral from primary physicians, and the short distance from home to clinics or hospitals in Korea might enable early detection and timely treatment for patients with nAMD. It has been established that a delay from symptoms to anti-VEGF treatment is associated with a reduced BCVA outcome. ${ }^{39,40}$ Timely initiation of anti-VEGF treatment might also explain the favourable visual outcome in the Korean nAMD population in the current study compared with previous realworld setting studies. $^{41}$

According to the approved label of Korea, the IVTAFL recommended dose for $\mathrm{nAMD}$ is three initial monthly doses, followed by one dose every 8 weeks. The use of initial monthly doses was known to be important for maximizing the initial visual gain and many previous studies highlighted the importance of this for VA improvements. ${ }^{30,42-44}$ Despite the real-world setting, $73.8 \%$ of patients received the three initial monthly doses in this study, and showed better treatment outcomes during the 8-month follow-up period than those who did not. The results of this PMS study, which are comparable to those of clinical trials, are assumed to be due to the stricter adherence to this initial treatment period in Korean patients with nAMD. Additionally, a high proportion of patients with PCV may have contributed to the results. In the current study, $26.5 \%$ were diagnosed with PCV, which may have been an underestimate given that indocyanine green angiography was not mandatory. Furthermore, patients with PCV achieved better treatment outcomes during the 8 months than patients without PCV. As the prevalence of PCV is known to be around 4-14\% in white patients with nAMD, this study included a higher incidence of PCV than in clinical trials. ${ }^{45}$ Because PCV takes a relatively stable long-term course of disease, patients with PCV may achieve relatively better efficacy on IVT-AFL than other types of nAMD, especially in the short term. ${ }^{46}$ In particular, since this study included more than $96 \%$ of patients with a disease duration of less than 1 month and evaluated the short-term efficacy for 8 months, eyes with PCV would achieve better treatment outcomes for IVT-AFL. Simple comparisons should be interpreted with caution, in view of inevitable differences in baseline characteristics between subgroups, as it is an observational study. However, even after adjusting for the confounding factors, the multivariate regression analysis demonstrated the injection number and subtype of nAMD (PCV or not) to be potential prognostic predictors for treatment of nAMD. The association of worse baseline BCVA with better VA gain and thinner baseline CRT with better CRT reduction is also generally consistent with previous studies. $^{47-51}$ These determinants related to treatment 
response of IVT-AFL to nAMD from real-world data would be informative for managing treatment.

The incidence rate of systemic and ocular AEs was under $2 \%$ during the observation period $(1.22 \%$ and $1.83 \%$, respectively). Of these, there were 3 serious ADRs including one case each of transient ischemic attack, endophthalmitis, and macular hole. The safety outcome of this study revealed lower incidence than in VIEW, possibly due to differences in reporting of AEs between randomised and observational studies, with the possibility of under-reporting. These findings were, however, consistent with the known safety profile of IVT-AFL in nAMD. ${ }^{10}$

There are several limitations of this observational study. First, there were no detailed inclusion and exclusion criteria. Thus, heterogeneous nAMD patients with wide spectrums of baseline clinical characteristics were included, who were treated using different retreatment criteria and follow-up intervals per standard practices at each center. This might have affected the outcome analysis; but conversely, it can also be considered a strength of the study, since it could reveal the treatment outcomes in real clinical practice and provide answers to questions that even well-designed clinical trials cannot address. Second, the follow-up period was relatively short at 8 months. Exploring long-term outcomes of anti-VEGF treatment in nAMD is important given the chronic nature of the disease. An extended study with longer follow-up would be needed. Third, due to the nature of a realworld-based study, different patients can contribute to the data observed at each visit. Considering this, LOCF was used for analysis, but since LOCF analysis relies on the assumption that BCVA and CRT remain constant after loss to followup, this can inflate or deflate study results due to this assumption method. Finally, BCVA was measured with Snellen and then converted to $\log$ MAR scale for analysis, making it difficult to accurately compare it with randomised controlled trial data.

In conclusion, this observational PMS study showed the effectiveness and safety of IVT-AFL in more than 3000 Asian patients with nAMD in real clinical practice. Intravitreal aflibercept injections for nAMD showed effectiveness and safety comparable to that in clinical trials, even though this study was a real-world clinical practice study with fewer injections. In particular, the patients who received three initial monthly injections and patients with PCV subtype showed better treatment response. Both number of injections and PCV were important determinants for improved treatment outcomes. During this observational study, there were no new safety signals and safety profile was maintained. This real-world study showed that intravitreal aflibercept treatment was effective and well tolerated in a real-world setting with a large number of Asian patients with nAMD.

\section{Data Sharing Statement}

The datasets used and/or analyzed during the current study are available from the corresponding author on reasonable request.

\section{Statement of Ethics}

Before conducting the study, institutional ethics approval was obtained from the Institutional Review Board of each participating study sites and the study was registered on ClinicalTrials.gov (NCT01783925). A complete list of study sites and investigators is in the Supplementary Table S7. Patients have given their written informed consent. All decisions in terms of diagnostic procedures, treatments, and management of the disease were fully dependent on mutual agreements between the patients and the investigator, following the principles of the Declaration of Helsinki.

\section{Acknowledgments}

The authors thank the investigators and their patients who participated in this PMS study. The authors thank Hyeseon Lee from Dream CIS Ltd., for medical writing and editorial support for this manuscript.

\section{Disclosure}

Min Sagong received research grants and consultation fees from Bayer, Novartis, and Allergan. Guihyun Moon is an employee of Bayer Korea, Seoul, Republic of Korea; also reports that Bayer Korea sponsored the study and was involved in the study conception, design, protocol writing, study coordination, data analysis, data interpretation, manuscript writing, editing, and submission, and reports that Dream CIS company, was a Contract research organization involved with data analysis, manuscript preparation and editing. Gahyung Ryu has nothing to declare. Donghyoun Noh has nothing to declare.

\section{References}

1. Bressler NM. Age-related macular degeneration is the leading cause of blindness. JAMA. 2004;291(15):1900-1901. doi:10.1001/jama.291.15. 1900

2. Resnikoff S, Pascolini D, Etya'Ale D, et al. Global data on visual impairment in the year 2002. Bull World Health Organ. 2004; $82: 844-851$ 
3. Rozing MP, Durhuus JA, Nielsen MK, et al. Age-related macular degeneration: a two-level model hypothesis. Prog Retin Eye Res. 2019;76:100825.

4. García-Layana A, García-Arumí J, Figueroa M, Arias Barquet L, Ruíz-Moreno J, Monclús-Arbona L. Management of wet age-related macular degeneration in Spain: challenges for treat and extend implementation in routine clinical practice. J Ophthalmol. 2019;2019:1-10. doi:10.1155/2019/9821509

5. Wong WL, Su X, Li X, et al. Global prevalence of age-related macular degeneration and disease burden projection for 2020 and 2040: a systematic review and meta-analysis. Lancet Glob Health. 2014;2(2):e106-e116. doi:10.1016/S2214-109X(13)70145-1

6. Flaxel CJ, Adelman RA, Bailey ST, et al. Age-related macular degeneration preferred practice pattern ${ }^{\circledR}$. Ophthalmology. 2020;127 (1):P1-P65.

7. Rosenfeld PJ, Brown DM, Heier JS, et al. Ranibizumab for neovascular age-related macular degeneration. $N$ Engl J Med. 2006;355 (14):1419-1431. doi:10.1056/NEJMoa054481

8. Brown DM, Kaiser PK, Michels M, et al. Ranibizumab versus verteporfin for neovascular age-related macular degeneration. $N$ Engl $J$ Med. 2006;355(14):1432-1444. doi:10.1056/NEJMoa062655

9. Group CR. Ranibizumab and bevacizumab for neovascular age-related macular degeneration. $N$ Engl J Med. 2011;364 (20):1897-1908.

10. Heier JS, Brown DM, Chong V, et al. Intravitreal aflibercept (VEGF trap-eye) in wet age-related macular degeneration. Ophthalmology. 2012;119(12):2537-2548. doi:10.1016/j.ophtha.2012.09.006

11. Ferreira A, Sagkriotis A, Olson M, Lu J, Makin C, Milnes F. Treatment frequency and dosing interval of ranibizumab and aflibercept for neovascular age-related macular degeneration in routine clinical practice in the USA. PLoS One. 2015;10(7):e0133968. doi:10.1371/journal.pone. 0133968

12. Holekamp NM, Liu Y, Yeh W-S, et al. Clinical utilization of anti-VEGF agents and disease monitoring in neovascular age-related macular degeneration. Am J Ophthalmol. 2014;157 (4):825-833. e821. doi:10.1016/j.ajo.2013.12.018

13. Johnston SS, Wilson K, Huang A, Smith D, Varker H, Turpcu A. Retrospective analysis of first-line anti-vascular endothelial growth factor treatment patterns in wet age-related macular degeneration. Adv Ther. 2013;30(12):1111-1127. doi:10.1007/s12325-013-0078-4

14. Maruko I, Iida T, Saito M, Nagayama D, Saito K. Clinical characteristics of exudative age-related macular degeneration in Japanese patients. Am J Ophthalmol. 2007;144(1):15-22. e12. doi:10.1016/j. ajo.2007.03.047

15. Yannuzzi LA, Wong DW, Sforzolini BS, et al. Polypoidal choroidal vasculopathy and neovascularized age-related macular degeneration. Arch Ophthalmol. 1999;117(11):1503-1510. doi:10.1001/archopht.11 7.11.1503

16. Sho K, Takahashi K, Yamada H, et al. Polypoidal choroidal vasculopathy: incidence, demographic features, and clinical characteristics. Arch Ophthalmol. 2003;121(10):1392-1396. doi:10.1001/archopht. 121.10.1392

17. Wen F, Chen C, Wu D, Li H. Polypoidal choroidal vasculopathy in elderly Chinese patients. Graefes Arch Clin Exp Ophthalmol. 2004;242(8):625-629. doi:10.1007/s00417-003-0667-z

18. Byeon SH, Lee SC, Oh H-S, Kim SS, Koh HJ, Kwon OW. Incidence and clinical patterns of polypoidal choroidal vasculopathy in Korean patients. Jpn J Ophthalmol. 2008;52(1):57-62. doi:10.1007/s10384007-0498-2

19. Laude A, Cackett PD, Vithana EN, et al. Polypoidal choroidal vasculopathy and neovascular age-related macular degeneration: same or different disease? Prog Retin Eye Res. 2010;29(1):19-29. doi:10.1016/j.preteyeres.2009.10.001

20. Lim LS, Cheung CMG, Wong TY. Asian age-related macular degeneration: current concepts and gaps in knowledge. Asia Pac J Ophthalmol. 2013;2(1):32-41. doi:10.1097/APO.0b013e31827ff5bc
21. Yannuzzi LA, Negrão S, Tomohiro I, et al. Retinal angiomatous proliferation in age-related macular degeneration. Retina. 2012;32:416-434. doi:10.1097/IAE.0b013e31823f9b3b

22. Chang W, Noh DH, Sagong M, Kim IT. Pharmacogenetic association with early response to intravitreal ranibizumab for age-related macular degeneration in a Korean population. Mol Vis. 2013;19:702.

23. Holash J, Davis S, Papadopoulos N, et al. VEGF-Trap: a VEGF blocker with potent antitumor effects. Proc Natl Acad Sci. 2002;99 (17):11393-11398. doi:10.1073/pnas.172398299

24. Stewart MW, Rosenfeld PJ. Predicted biological activity of intravitreal VEGF Trap. Br J Ophthalmol. 2008;92(5):667-668. doi:10. 1136/bjo.2007.134874

25. Kim JH, Lee DW, Chang YS, Kim JW, Kim CG. Twelve-month outcomes of treatment using ranibizumab or aflibercept for neovascular age-related macular degeneration: a comparative study. Graefes Arch Clin Exp Ophthalmol. 2016;254(11):2101-2109. doi:10.1007/ s00417-016-3353-7

26. Kang HM, Koh HJ. Long-term visual outcome and prognostic factors after intravitreal ranibizumab injections for polypoidal choroidal vasculopathy. Am J Ophthalmol. 2013;156(4):652-660. e651. doi:10.1016/j.ajo.2013.05.038

27. Shin JY, Yu HG. Optical coherence tomography-based ranibizumab monotherapy for retinal angiomatous proliferation in Korean patients. Retina. 2014;34(12):2359-2366. doi:10.1097/IAE.0000000000000225

28. Ogura Y, Terasaki H, Gomi F, et al. Efficacy and safety of intravitreal aflibercept injection in wet age-related macular degeneration: outcomes in the Japanese subgroup of the VIEW 2 study. $\mathrm{Br}$ J Ophthalmol. 2015;99(1):92-97.

29. Lee FL, Kwon OW, Chung H, Lai CC, Sheu SJ, Yoon YH. Ranibizumab in South Korean and Taiwanese patients with age-related macular degeneration: primary outcome of the EXTEND III study. Acta Ophthalmol. 2012;90(5):e406-407. doi:10.1111/j.1755-3768.2011.02262.x

30. Holz FG, Tadayoni R, Beatty S, et al. Multi-country real-life experience of anti-vascular endothelial growth factor therapy for wet age-related macular degeneration. $\mathrm{Br} \quad J$ Ophthalmol. 2015;99 (2):220-226. doi:10.1136/bjophthalmol-2014-305327

31. Monés J, Singh RP, Bandello F, Souied E, Liu X, Gale R. Undertreatment of neovascular age-related macular degeneration after 10 years of anti-vascular endothelial growth factor therapy in the real world: the need for a change of mindset. Ophthalmologica. 2020;243(1):1-8. doi:10.1159/000502747

32. Ciulla TA, Huang F, Westby K, Williams DF, Zaveri S, Patel SC. Real-world outcomes of anti-vascular endothelial growth factor therapy in neovascular age-related macular degeneration in the United States. Ophthalmol Retina. 2018;2(7):645-653. doi:10.1016/j.oret.20 18.01.006

33. Weber M, Velasque L, Coscas F, Faure C, Aubry I, Cohen SY. Effectiveness and safety of intravitreal aflibercept in patients with wet age-related macular degeneration treated in routine clinical practices across France: 12-month outcomes of the RAINBOW study. BMJ Open Ophthalmol. 2019;4(1):e000109. doi:10.1136/bmjophth-2017-000109

34. Gillies MC, Nguyen V, Daien V, Arnold JJ, Morlet N, Barthelmes D. Twelve-month outcomes of ranibizumab vs. aflibercept for neovascular age-related macular degeneration: data from an observational study. Ophthalmology. 2016;123(12):2545-2553. doi:10.1016/j. ophtha.2016.08.016

35. Eleftheriadou M, Vazquez-Alfageme C, Citu CM, et al. Long-term outcomes of aflibercept treatment for neovascular age-related macular degeneration in a clinical setting. $A m \quad J$ Ophthalmol. 2017;174:160-168. doi:10.1016/j.ajo.2016.09.038

36. Framme C, Eter N, Hamacher T, et al. Aflibercept for patients with neovascular age-related macular degeneration in routine clinical practice in Germany: twelve-month outcomes of PERSEUS. Ophthalmol Retina. 2018;2(6):539-549. doi:10.1016/j.oret.2017.09.017 
37. Lotery A, Griner R, Ferreira A, Milnes F, Dugel P. Real-world visual acuity outcomes between ranibizumab and aflibercept in treatment of neovascular AMD in a large US data set. Eye. 2017;31 (12):1697-1706. doi:10.1038/eye.2017.143

38. Providência J, Rodrigues TM, Oliveira M, et al. Real-world results of aflibercept versus ranibizumab for the treatment of exudative AMD using a fixed regimen. Biomed Res Int. 2018;2018:1-7. doi:10.1155/ 2018/9276580

39. Lim JH, Wickremasinghe SS, Xie J, et al. Delay to treatment and visual outcomes in patients treated with anti-vascular endothelial growth factor for age-related macular degeneration. Am J Ophthalmol. 2012;153(4):678-686. e672. doi:10.1016/j.ajo.2011. 09.013

40. Arpa C, Khalid H, Chandra S, et al. Ten-year survival trends of neovascular age-related macular degeneration at first presentation. Br J Ophthalmol. 2020. doi:10.1136/bjophthalmol-2020-317161

41. Bloch SB, la Cour M, Sander B, et al. Predictors of 1-year visual outcome in neovascular age-related macular degeneration following intravitreal ranibizumab treatment. Acta Ophthalmol. 2013;91 (1):42-47. doi:10.1111/j.1755-3768.2011.02268.x

42. Holz FG, Figueroa MS, Bandello F, et al. Ranibizumab treatment in treatment-naive neovascular age-related macular degeneration: results from LUMINOUS, a global real-world study. Retina (Philadelphia, Pa). 2020;40(9):1673. doi:10.1097/IAE.0000000000002670

43. Cohen SY, Mimoun G, Oubraham H, et al. Changes in visual acuity in patients with wet age-related macular degeneration treated with intravitreal ranibizumab in daily clinical practice: the LUMIERE study. Retina. 2013;33(3):474-481. doi:10.1097/IAE.0b013e31827b6324

44. Menon G, Chandran M, Sivaprasad S, Chavan R, Narendran N, Yang Y. Is it necessary to use three mandatory loading doses when commencing therapy for neovascular age-related macular degeneration using bevacizumab?(BeMOc Trial). Eye. 2013;27(8):959-963. doi:10.1038/eye.2013.93
45. Hatz K, Prünte C, Bloch SB, la Cour M, Sander B. Polypoidal choroidal vasculopathy in Caucasian patients with presumed neovascular age-related macular degeneration and poor ranibizumab response. $\mathrm{Br}$ $J$ Ophthalmol. 2014;98(2):188-194. doi:10.1136/bjophthalmol-2013303444

46. Moorthy RS, Lyon AT, Rabb MF, Spaide RF, Yannuzzi LA, Jampol LM. Idiopathic polypoidal choroidal vasculopathy of the macula. Ophthalmology. 1998;105(8):1380-1385. doi:10.1016/S01 61-6420(98)98016-2

47. Ying G-S, Huang J, Maguire MG, et al. Baseline predictors for one-year visual outcomes with ranibizumab or bevacizumab for neovascular age-related macular degeneration. Ophthalmology. 2013;120 (1):122-129. doi:10.1016/j.ophtha.2012.07.042

48. Simader C, Ritter M, Bolz M, et al. Morphologic parameters relevant for visual outcome during anti-angiogenic therapy of neovascular age-related macular degeneration. Ophthalmology. 2014;121 (6):1237-1245. doi:10.1016/j.ophtha.2013.12.029

49. Suzuki M, Nagai N, Izumi-Nagai K, et al. Predictive factors for non-response to intravitreal ranibizumab treatment in age-related macular degeneration. $\mathrm{Br} J$ Ophthalmol. 2014;98(9):1186-1191. doi:10.1136/bjophthalmol-2013-304670

50. Regillo CD, Busbee BG, Ho AC, Ding B, Haskova Z. Baseline predictors of 12-month treatment response to ranibizumab in patients with wet age-related macular degeneration. Am J Ophthalmol. 2015;160(5):1014-1023. e1012. doi:10.1016/j.ajo.2015.07.034

51. Schwartz R, Loewenstein A. Early detection of age related macular degeneration: current status. Int J Retina Vitreous. 2015;1(1):1-8. doi:10.1186/s40942-015-0022-7
Clinical Ophthalmology

\section{Publish your work in this journal}

Clinical Ophthalmology is an international, peer-reviewed journal covering all subspecialties within ophthalmology. Key topics include: Optometry; Visual science; Pharmacology and drug therapy in eye diseases; Basic Sciences; Primary and Secondary eye care; Patient Safety and Quality of Care Improvements. This journal is indexed on PubMed
Dovepress

Central and CAS, and is the official journal of The Society of Clinical Ophthalmology (SCO). The manuscript management system is completely online and includes a very quick and fair peer-review system, which is all easy to use. Visit http://www.dovepress.com/ testimonials.php to read real quotes from published authors. 